\title{
Preoperative diagnosis of cavernous hemangioma presenting with melena using wireless capsule endoscopy of the small intestine
}

Authors

Institutions
Yu Akazawa' ${ }^{1}$, Katsushi Hiramatsu', Takuto Nosaka', Yasushi Saito ${ }^{1}$, Yoshihiko Ozaki', Kazuto Takahashi', Tatsushi Naito ${ }^{1}$, Kazuya Ofuji', Hidetaka Matsuda ${ }^{1}$, Masahiro Ohtani ${ }^{1}$, Tomoyuki Nemoto ${ }^{1}$, Hiroyuki Suto ${ }^{1}$, Akio Yamaguchi ${ }^{2}$, Yoshiaki Imamura ${ }^{3}$, Yasunari Nakamoto ${ }^{1}$

${ }^{1}$ Second Department of Internal Medicine

${ }^{2}$ First Department of Surgery, Faculty of Medical Sciences, Fukui University

${ }^{3}$ Division of Surgical Pathology, University of Fukui Hospital, Fukui, Japan submitted 26. October 2016 accepted after revision 9. December 2015

\section{Bibliography}

Dol http://dx.doi.org/

10.1055/s-0041-111321

Published online: 4.2.2016

Endoscopy International Open 2016; 04: E249-E251

(c) Georg Thieme Verlag KG Stuttgart . New York

E-ISSN 2196-9736

\section{Corresponding author}

Yasunari Nakamoto, MD, PhD

Second Department of Internal Medicine

Faculty of Medical Sciences,

Fukui University

23-3 Matsuoka Shimoaizuki,

Eiheiji-cho, Yoshida-gun

Fukui 910-1193

Japan

Phone: +81-776-61-8351

Fax: +81-776-61-8110

nakamoto-med2@med.u-fukui. ac.jp
Background and study aims: Primary neoplasms of the small intestine are relatively rare in all age groups, accounting for about $5 \%$ of all gastrointestinal tumors [1]. Cavernous hemangiomas of the small intestine are also rare, can cause gastrointestinal bleeding, and are extremely difficult to

\section{Introduction \\ $\nabla$}

Cavernous hemangioma of the small intestine is a rare disease. Because hemangiomas can cause massive gastrointestinal bleeding, emergency surgery may be required; however, the preoperative diagnosis of these growths is difficult. Here, we report a case of cavernous hemangioma of the small intestine that was diagnosed using wireless capsule endoscopy and single-balloon enteroscopy. Our patient presented with melena and iron deficiency anemia. Neither gastroscopy nor colonoscopy detected any remarkable findings. Thus, we performed wireless capsule endoscopy and single-balloon enteroscopy, which revealed a blue submucosal lesion (length, $2 \mathrm{~cm}$ ) with a small red spot on its surface in the distal jejunum. Accordingly, we diagnosed the lesion as a cavernous hemangioma. Laparoscopic-assisted small intestinal resection was performed successfully. This case highlights the usefulness of wireless capsule endoscopy of the small intestine as a diagnostic tool for preoperative detection of the causes of obscure gastrointestinal bleeding, including cavernous hemangioma of the small intestine.

\section{Case Report \\ $\nabla$}

A 56-year-old woman visited her local hospital because of worsening fatigue and melena that had persisted for a week. Gastroscopy and colonoscopy were performed but no active bleeding or lesions were detected. Because the patient's diagnose preoperatively [2]. We present a patient who presented with melena and iron deficiency anemia, for whom wireless capsule endoscopy and single-balloon enteroscopy facilitated the diagnosis of cavernous hemangioma.

symptoms persisted, she was referred and admitted to our hospital for further evaluation 50 days after her first visit to her local hospital. The woman had a history of surgery for uterine fibroid tumors and appendicitis. Furthermore, she had been receiving treatment for articular rheumatism at her local hospital. She had not been taking nonsteroidal anti-inflammatory or antiplatelet drugs.

On admission, physical examination of the patient revealed pale conjunctivae. A clinical examination of the abdomen did not detect any pain, masses, or vascular bruits. However, laboratory analysis revealed marked anemia (hemoglobin, $6.7 \mathrm{~g} / \mathrm{dL}$ ), and low serum iron and ferritin levels. The patient received a blood transfusion, and her hemoglobin levels improved $(>10 \mathrm{~g} / \mathrm{dL})$. An investigation of her small intestine was performed using a wireless capsule endoscope, and an elevated red lesion was found in the jejunum ( $\bullet$ Fig. 1 a). The lesion was not bleeding, and no other lesions were detected in the small intestine. On contrast-enhanced computed tomography, the mass (diameter, $2 \mathrm{~cm}$ ) showed enhancement and was located in the pelvic region of the small intestine ( $\bullet$ Fig. $\mathbf{1 b}$ ). Single-balloon enteroscopy performed using an antegrade approach revealed that the lesion was located in the distal jejunum, $1.5 \mathrm{~m}$ from Treitz's ligament. It was approximately $2 \mathrm{~cm}$ in diameter, appeared to be a submucosal tumor, and was blue with superficial red spots $(\bullet$ Fig.2). Based on the findings from wireless capsule endoscopy and single-balloon enteroscopy, we diagnosed the lesion as a cavernous hemangioma. 


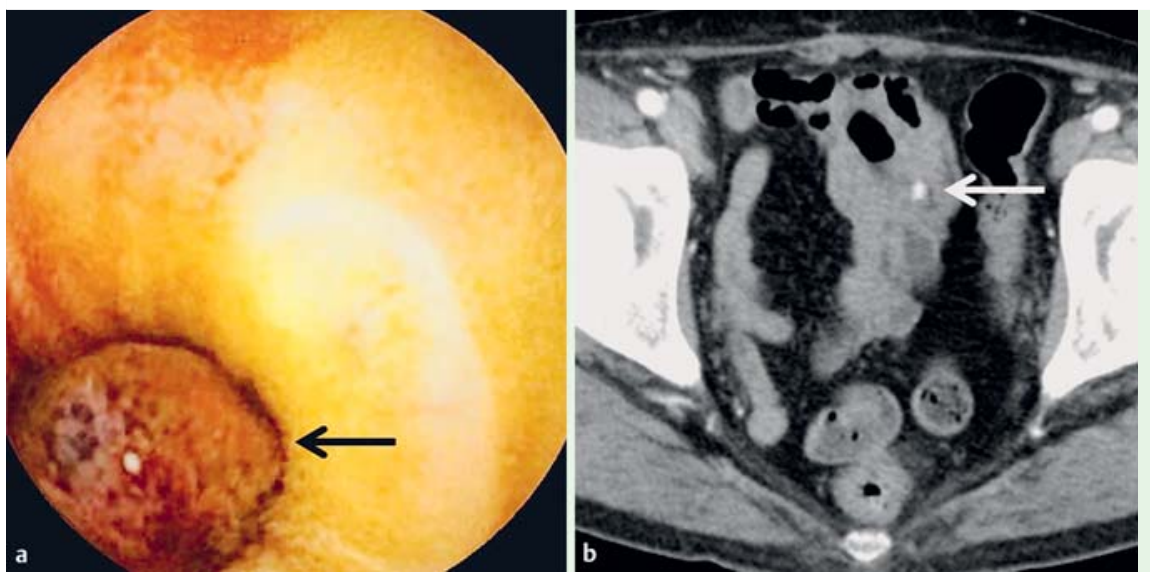

Fig. 1 a Wireless capsule endoscopy showing a reddish elevated lesion in the jejunum (black arrow). $\mathbf{b}$ Contrast-enhanced computed tomography of the abdomen and pelvis showing the mass exhibiting enhancement (white arrow).

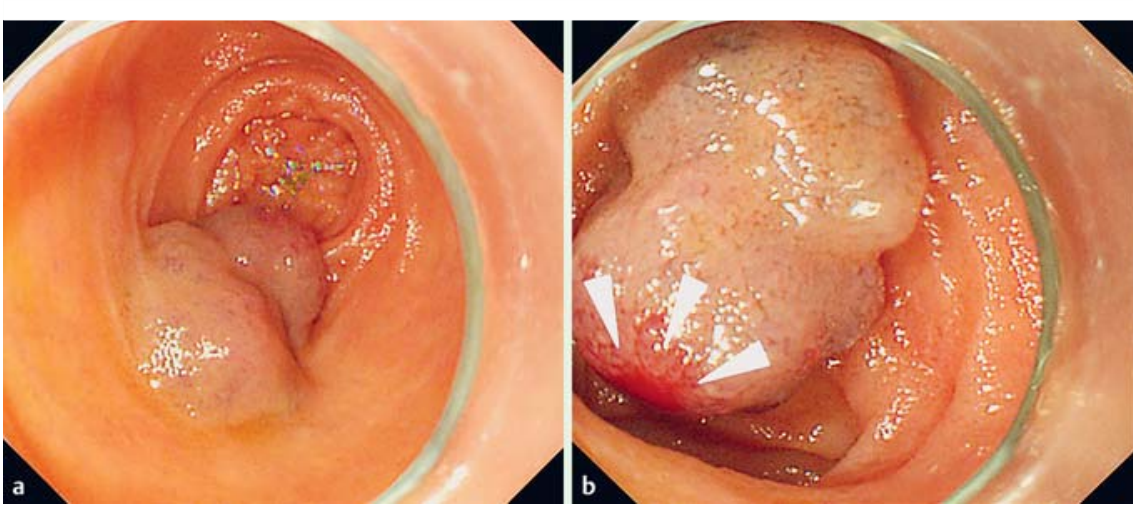

Fig. 2 Images of the Single-balloon enteroscopy. a The lesion showed a blue submucosal tumor. b The tumor had a red spot on the surface (arrow heads).
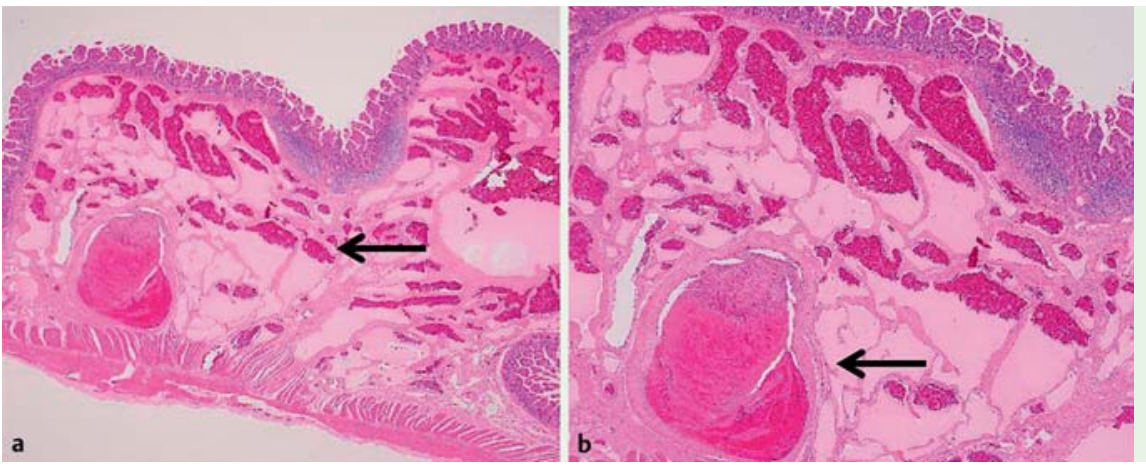

Fig. 3 Histologic image of the surgically resected tumor specimen. a The tumor was composed of numerous dilated, blood-filled vessels within the submucosal layer (black arrow) (hematoxylin-eosin stain, $\times 20)$. $\mathbf{b}$ Some vessels displayed thrombotic phenomena (black arrow) (hematoxylin-eosin stain, $\times 40)$.

On the 20th hospital day, laparoscopy-assisted small intestinal resection was performed with jejuno-jejunal reanastomosis. Macroscopic examination of the resected specimen revealed that the lesion measured $1.3 \times 1.0 \mathrm{~cm}$ and was elastic, soft, and purplish-blue. Pathological examination showed vascular proliferation within the submucosa; that is, large, dilated, blood-filled vessels lined by flattened endothelia (some of which displayed thrombotic phenomena) were observed ( $\bullet$ Fig. 3). The histological diagnosis was cavernous hemangioma of the small intestine. Postoperatively, the patient recovered well and her symptoms have not recurred.

\section{Discussion \\ $\nabla$}

Cavernous hemangioma of the small intestine is a rare disease, accounting for $5 \%$ to $10 \%$ of all small-bowel benign neoplasms [3]. Hemangioma accounted for 19 cases of 676 small intestinal tumors reported between January 1995 and December 1999 [4]. Of 144 cases of small intestinal tumors detected with double-bal- loon endoscopy between September 2000 and December 2005, hemangiomas were identified in 3 cases [5]. Although it is an uncommon cause of gastrointestinal bleeding, hemangioma of the small bowel often leads to the development of acute hemorrhage [6] or chronic anemia [7].

We retrieved from the PUBMED and i-chu-shi (Japan) databases reports of cavernous hemangiomas presenting with gastrointestinal bleeding that were published beginning in 2000; 46 cases (22 women, 24 men; mean age, 34.6 years) were retrieved and reviewed. The most common site of small intestinal hemangiomas was the jejunum (46\%), and melena was observed in $65 \%$ of the cases. The mean diameter of the lesions was $2.93 \mathrm{~cm}$. Twentytwo of the 46 lesions ( $48 \%$ ) were diagnosed preoperatively ( $\bullet$ Table 1) $[2,3,7,8]$. Of these cases, seven were detected with capsule endoscopy and 10 were diagnosed using balloon enteroscopy. Compared with the cases reported before 2000, a markedly increased proportion of cases were diagnosed preoperatively using capsule endoscopy and balloon enteroscopy from 2000 onward. According to the algorithms for the diagnosis and treatment of obscure gastrointestinal bleeding proposed by the American Gas- 
Table 1 Reports since 2000 on preoperative diagnosis of small intestinal cavernous hemangiomas.

\begin{tabular}{|c|c|c|c|c|c|c|c|}
\hline Author, Year & $\begin{array}{l}\text { Age } \\
\text { (years) }\end{array}$ & Sex & Symptom & $\begin{array}{l}\text { Preoperative diagnosis } \\
\text { examination }\end{array}$ & $\begin{array}{l}\text { Hemangioma } \\
\text { size }(\mathrm{cm})\end{array}$ & $\begin{array}{l}\text { Hemangioma } \\
\text { location }\end{array}$ & Treatment \\
\hline Shimizu et al., 2006 & 44 & M & Melena & Computed tomography & 2.0 & Ileum & Laparotomy \\
\hline Fukumura et al., 2006 & 9 & $\mathrm{~F}$ & Anemia & Colon endoscopy & 1.0 & Multiple & Laparotomy \\
\hline Zeng et al., 2008 & 21 & M & Abdominal pain & Computed tomography & 2.2 & Jejunum & Laparotomy \\
\hline Deng et al., 2008 & 6 & M & Melena & Balloon enteroscopy & 1.0 & Multiple & Conservative treatment \\
\hline Deng et al., 2008 & 6 & M & Melena & Balloon enteroscopy & 1.0 & Multiple & Conservative treatment \\
\hline Deng et al., 2008 & 7 & M & Melena & Balloon enteroscopy & 1.0 & Multiple & Conservative treatment \\
\hline Willert et al., 2008 [3] & 19 & $\mathrm{M}$ & Anemia & $\begin{array}{l}\text { Capsule endoscopy+ } \\
\text { balloon enteroscopy }\end{array}$ & 1.4 & Multiple & Endoscopic treatment \\
\hline Pinho et al., 2009 [2] & 9 & $\mathrm{~F}$ & Anemia & Capsule endoscopy & 2.5 & Ileum & NA \\
\hline Tsutsui et al., 2009 & 40 & $\mathrm{~F}$ & Anemia & Balloon enteroscopy & 5.0 & Jejunum & Laparotomy \\
\hline Morita et al., 2009 & 69 & M & Anemia & $\begin{array}{l}\text { Capsule endoscopy }+ \\
\text { balloon enteroscopy }\end{array}$ & 0.5 & Ileum & Laparoscopic operation \\
\hline Sakoda et al., 2009 & 40 & $\mathrm{~F}$ & Melena & Computed tomography & 6.0 & Jejunum & NA \\
\hline Endo et al., 2009 & 49 & $\mathrm{~F}$ & Melena & $\begin{array}{l}\text { Small intestinal } \\
\text { imaging }\end{array}$ & 1.2 & Multiple & Endoscopic treatment \\
\hline Takayama et al., 2010 & 71 & $\mathrm{~F}$ & Abdominal pain & Computed tomography & 3.0 & Ileum & Laparotomy \\
\hline Abdul Aziz et al., 2011 & 6 & $\mathrm{~F}$ & Abdominal pain & Ultrasonography & 15 & Ileum & Laparotomy \\
\hline $\begin{array}{l}\text { Rodriguez-Zentner et } \\
\text { al., } 2011\end{array}$ & 46 & M & Anemia & Colon endoscopy & 2.3 & lleum & Laparoscopic operation \\
\hline Mikami et al., 2011 & 45 & $\mathrm{~F}$ & Melena & $\begin{array}{l}\text { Capsule endoscopy + } \\
\text { balloon enteroscopy }\end{array}$ & 0.9 & Multiple & Endoscopic treatment \\
\hline Pera et al., 2012 [7] & 16 & M & Anemia & $\begin{array}{l}\text { Capsule endoscopy+ } \\
\text { balloon enteroscopy }\end{array}$ & 4.2 & Jejunum & Laparoscopic operation \\
\hline Guardiola et al., 2012 & 19 & M & Melena & Capsule endoscopy & 1.0 & Ileum & Laparoscopic operation \\
\hline Miyamoto et al., 2012 & 61 & $\mathrm{~F}$ & Anemia & Computed tomography & 4.0 & Ileum & Laparotomy \\
\hline $\begin{array}{l}\text { Dhumane et al., } 2013 \\
\text { [8] }\end{array}$ & 60 & M & Anemia & $\begin{array}{l}\text { Capsule endoscopy+ } \\
\text { balloon enteroscopy }\end{array}$ & 7.0 & Jejunum & Laparoscopic operation \\
\hline Tanioka T et al., 2013 & 16 & $\mathrm{~F}$ & Anemia & Balloon enteroscopy & 1.5 & Jejunum & Laparoscopic operation \\
\hline Sato M et al., 2013 & 9 & $\mathrm{~F}$ & Abdominal pain & Computed tomography & 2.5 & Jejunum & Laparotomy \\
\hline Our case, 2013 & 56 & $\mathrm{~F}$ & Melena & $\begin{array}{l}\text { Capsule endoscopy+ } \\
\text { balloon enteroscopy }\end{array}$ & 1.3 & Jejunum & Laparoscopic operation \\
\hline
\end{tabular}

M, male; F, female; NA, not available

troenterological Association in 2007, capsule endoscopy should be used for the initial examination. When positive findings are acquired, balloon enteroscopy should be performed [9]. In the current case, capsule endoscopy and balloon enteroscopy were performed based on these guidelines, and we were able to detect the characteristic findings of cavernous hemangioma, e.g., a blue submucosal lesion with a bleeding spot on its surface.

Regarding the treatment of bleeding hemangiomas, most of the previous cases were treated surgically [10]. Endoscopic treatment was performed in only three cases. One of the hemangiomas was clipped, another was subjected to sclerotherapy, and the third was removed by means of snare polypectomy [3]. In these three cases, bleeding occurred frequently, and the multiple lesions were relatively small. In our case, we did not perform endoscopic treatment because active bleeding was not present at that time, and there seemed to be a risk for massive bleeding after endoscopic treatment. Future studies are needed to determine the indications for endoscopic treatment.

In conclusion, we encountered a case of cavernous hemangioma of the small intestine that was diagnosed preoperatively using wireless capsule endoscopy. Capsule endoscopy is clearly useful for preoperative diagnosis of hemangiomas in the small intestine.

Competing interests: None

\section{References}

1 de Mascarenhas-Saraiva M, da Silva Araújo Lopes LM. Small-bowel tumors diagnosed by wireless capsule endoscopy: report of five cases. Endoscopy 2003; 35: 865-868

2 Pinho R, Rodrigues A, Proenca L et al. Solitary hemangioma of the small bowel disclosed by wireless capsule endoscopy. Gastroenterol Clin Biol 2008; 32: $15-18$

3 Willert RP, Chong AK. Multiple cavernous hemangiomas with iron deficiency anemia successfully treated with double-balloon enteroscopy. Gastrointest Endosc 2008; 67: 765-767

4 Yao T, Yao T, Furukawa K et al. Primary small intestinal tumors. Stom Intest 2001; 36: $871-881$

5 Mitsui K, Tanaka S, Yamamoto $H$ et al. Role of double-balloon endoscopy in the diagnosis of small-bowel tumors: the first Japanese multicenter study. Gastrointest Endosc 2009; 70: 498-504

6 Ohira S, Hasegawa H, Ogiso $S$ et al. A case of hemangioma of the small intestine in which the region could be diagnosed preoperatively. Nihon Shokakibyo Gakkai Zasshi 2003; 100: 166 - 169

7 Pera M, Márquez L, Dedeu JM et al. Solitary cavernous hemangioma of the small intestine as the cause of long-standing iron deficiency anemia. J Gastrointest Surg 2012; 16: 2288 -2290

8 Dhumane P, Mutter D, D'Agostino J et al. Small bowel exploration and resection using single-port surgery: a safe and feasible approach. Colorectal Dis 2013; 15: 109-114

9 Raju GS, Gerson L, Das A et al. American Gastroenterological Association (AGA) Institute technical review on obscure gastrointestinal bleeding. Gastroenterology 2007; 133: 1697-1717

10 Khurana V, Dala R, Barkin JS. Small bowel cavernous hemangioma. Gastrointest Endosc 2004; 60: 96 